\title{
Evaluation of chemical immobilization treatments for reducing arsenic transport in red mud
}

\author{
Yiran Li $\cdot$ Jun Wang $\cdot$ Yi Su $\cdot$ Xianjia Peng $\cdot$ \\ Jinhui Liu $\cdot$ Zhaokun Luan
}

Received: 30 May 2012/Accepted: 15 January 2013/Published online: 3 February 2013

(c) Springer-Verlag Berlin Heidelberg 2013

\begin{abstract}
Red mud (RM) was produced during alumina production from bauxite known as the Bayer process. Arsenic was detected in the solid phase of RM (RMsf) which was disposed in the disposal area. This study investigates the effectiveness of using Zero-valent iron (ZVI), ferrihydrite, ferrous sulfate $\left(\mathrm{FeSO}_{4}\right)$, waste acid (WA) or $\mathrm{CO}_{2}$ for immobilization of arsenic in the RMsf. To test the effect of the amendments on the arsenic leachability, the RMsf samples were amended with the iron-based materials or acidifiers at various w/w (weight/ weight) ratios (1-10\%) for 30 days. The leachability of arsenic in the RMsf was evaluated by a 4-step water elusion process. After 30-day treatment of the RMsf, the leachability of As decreased from an initial (12.7\%) to $(7.0 \%)$ with a w/w ratio of $5 \%$ ZVI $(0 \%)$ with $5 \%$ $\mathrm{FeSO}_{4} \cdot 7 \mathrm{H}_{2} \mathrm{O},(3.4 \%)$ with $5 \%$ ferryhydrite, $(2.0 \%)$ with $6 \%$ WA and $(11.8 \%)$ with $6 \% \mathrm{CO}_{2} . \mathrm{FeSO}_{4} \cdot 7 \mathrm{H}_{2} \mathrm{O}$ and WA showed more effectively than other amendments
\end{abstract}

Y. Li · J. Liu

Department of Water Resources and Environmental Engineering, East China Institute of Technology, Fuzhou 344000, Jiangxi, People's Republic of China e-mail: lyr2006xd@yahoo.com.cn

J. Wang $(\bowtie) \cdot$ X. Peng $\cdot$ Z. Luan

State Key Laboratory of Environmental Aquatic Chemistry, Research Center for Eco-Environmental Sciences, Chinese Academy of Sciences, P.O. Box 2871, Beijing 100085, People's Republic of China e-mail: junwang@rcees.ac.cn

Y. Su

School of Chemical and Environmental Engineering, China University of Mining and Technology, Beijing 100083, People's Republic of China for immobilizing arsenic. Arsenic fractionation with a sequential extraction procedure was used to evaluate the arsenic migration potential in the RMsf. $\mathrm{FeSO}_{4}$ and WA were effective in increasing the hydrous oxide combined arsenic in the RMsf. The leachable $\mathrm{Cl}^{-}$and $\mathrm{SO}_{4}{ }^{2-}$ in the RMsf increased from 2.9 to $14.1 \mathrm{mg} / \mathrm{g}$ and $19.9-44.4 \mathrm{mg} / \mathrm{g}$ with $6 \% \mathrm{WA}$ and $5 \% \mathrm{FeSO}_{4} \cdot 7 \mathrm{H}_{2} \mathrm{O}$ added, respectively. The estimated cost of the $\mathrm{FeSO}_{4}$ and WA treatment was 0.47 and 0.49 USD per ton, respectively.

Keywords Red mud · Arsenic immobilization · Iron oxide $\cdot$ Acidifier

\section{Introduction}

Red mud (RM) is the caustic waste material of bauxite ore processing for alumina extraction. Generally, $1-1.5$ tons of RM will be produced with each ton of alumina produced. Until 2009, about 120 million tons of alumina are produced per annum all over the world (Klauber et al. 2009). RM has accumulated over the years and caused a serious environmental problem because of its high alkalinity and large amount (Sushil and Batra 2008).

$\mathrm{RM}$ is usually as a mixture of solid phase (RMsf) and liquid phase (RMlf). The RMsf is disposed of in the disposal area after solid-liquid separation. The RMlf is recycled to the alumina production or discharged after treatment. The chemical compositions of the RM were affected by bauxites and additives in alumina production. Arsenic was detected as a harmful component in the RMlf as described in previous work ( $\mathrm{Li}$ et al. 2012). Arsenic accumulated in the RMlf during alumina production, and parts of arsenic contained in the RMsf were disposed of in the RM disposal area. 
It was widely reported that RM could be an effective adsorbent for arsenic treatment because of the hematite contained ( $\mathrm{Li}$ et al. 2010; Soner Altundogan et al. 2000). However, high alkalinities in the RM disposal area inhibited arsenic immobilization. The mobilized arsenic poses a great threat to the ground and surface water in the RM disposal area. Therefore, arsenic immobilization is significant in the RM disposal area. Chemical immobilization of arsenic has been successfully reported in treating As-contaminated soil and tailing materials. Iron salts with and without $\mathrm{pH}$ buffering were added to prevent As mobilization (Miretzky and Cirelli 2010; Seidel et al. 2005; Zhang and Pu 2011).

Iron salts were widely reported for the good affinity with arsenic. Zerovalent iron (ZVI), ferrous and ferrihydrite were investigated for arsenic immobilization in soil. The mechanisms for arsenic uptake by ZVI, ferrous or ferrihydrite have been extensively studied (Bang et al. 2005; Tokoro et al. 2009; Xenidis et al. 2010). Iron-arsenic coprecipitation and surface complexation were the main mechanism for arsenic uptake by iron (oxides).

Arsenic immobilization in the RM disposal area has not been reported previously. The chemical compositions of the RMsf were different from soils and other tailing materials. The complex chemical compositions of the RMsf, especially the high alkalinities, could affect the arsenic immobilization efficiency. Meanwhile, hematite in the RMsf was advantaged for arsenic immobilization in neutral or acid conditions. Therefore, a feasible and costeffective technology with high arsenic immobilization efficiency is significant for the RMsf treatment. The main objective of this work was to investigate a practical technology for arsenic immobilization in the RMsf. The effects of arsenic immobilization technologies by iron (oxides) or acidifiers in treating RMsf were evaluated.

\section{Materials and methods}

\section{RMsf samples}

The RMsf samples were provided by the No. 2 factory of Shandong Branch, Aluminum Corporation of China. The RMsf samples were collected after the solid-liquid separation of RM, as shown in Fig. 1. The RMsf samples were collected in October 2010.

The RMsf was collected then stored under airtight conditions. To evaluate the RMsf chemical compositions, the RMsf samples were dried at $75^{\circ}$. The chemical compositions of the RMsf samples were measured by ICP-AES. To prepare the RMsf samples for ICP-AES analysis, the dried solid samples were digested [Aqua regia $(3+1 \mathrm{HCl}-$ $\mathrm{HNO}_{3}$ )] by a microwave oven (MARS, CEM). An X-ray

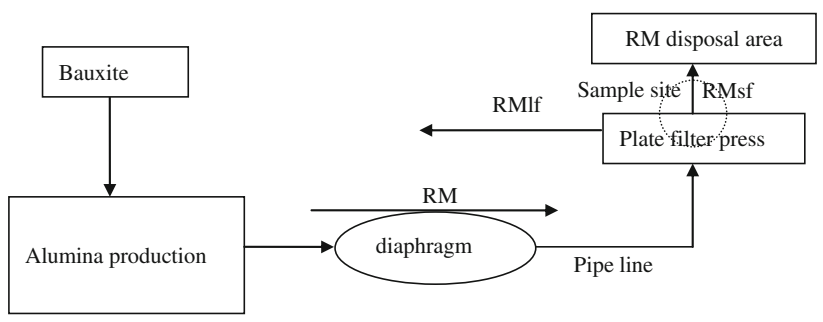

Fig. 1 Schematic explanation of the fate of RM after alumina production

diffractometer (ShimadzuXRD-6000) operated at $40 \mathrm{kV}$ and $30 \mathrm{~mA}$. $\mathrm{Cu} \mathrm{Ka}(l=0.15418 \mathrm{~nm})$ radiation over the range of 2 from $10^{\circ}$ to $80^{\circ}$ was used to identify the crystal structure and crystallinity.

Arsenic chemical immobilization

The arsenic immobilization by the following amendments was evaluated: (1) ZVI (AR); (2) Ferrous sulfate, FeS$\mathrm{O}_{4} \cdot 7 \mathrm{H}_{2} \mathrm{O}$ (AR); (3) Ferrihydrite; (4) Waste acid (WA); (5) Carbon dioxide, $\mathrm{CO}_{2}$. ZVI was provided by Shanghai Aibi Chemistry Preparation Co.. The iron content in ZVI was higher than $98 \%$. The iron filings were sieved to constrain the grain size smaller than $0.125 \mathrm{~mm}$. The laboratory ferrihydrite synthesis was described as follows. To $500 \mathrm{ml}$ of a solution containing $1 \mathrm{M}$ of $\mathrm{Na}_{2} \mathrm{CO}_{3}, 1 \mathrm{M} \mathrm{FeCl}$ was added at a fixed rate of addition of approximately $100 \mathrm{ml} / \mathrm{min}$, during vigorous stirring with a magnetic stirrer. The $\mathrm{pH}$ of the suspension was then adjusted to 7.5 by the drop wise addition of $1 \mathrm{M} \mathrm{FeCl}_{3}$. The sediment was washed thrice with deionized water and separated from solution by $10 \mathrm{~min}$ centrifugation at $5,000 \mathrm{rpm}$. The centrifugation sediment was re-suspended in deionized water, diluted to $200 \mathrm{ml}$ final volume, and stored at room temperature. The ferrihydrite concentration in the final suspension was approximately $0.1 \mathrm{~g} / \mathrm{ml}$. Industrial waste acid (WA, mainly hydrochloric acid) was provided by Zibo City Economic and Trade Co., the free $\mathrm{H}^{+}$concentration in WA was $5.9 \mathrm{M}$. ZVI, ferrous sulfate, ferrihydrite and WA were thoroughly incorporated into RMsf in a glass breaker. Carbon dioxide $\left(\mathrm{CO}_{2}\right)$ was provided by a high-pressure gas cylinder, a slow aeration rate of $20 \mathrm{ml} / \mathrm{min}$ was controlled by a rotameter. An amount of $150 \mathrm{~g}$ RMsf and $50 \mathrm{ml}$ deionized water was added in a $250 \mathrm{ml}$ breaker. The aeration tube with a gas distribution head was connected with the rotameter. The gas distribution head was covered by RMsf. The RMsf was mixed with $\mathrm{CO}_{2}$ gas by agitation at $500 \mathrm{rpm}$.

The amendments were quantitatively added in the RMsf. The treated RMsf was sealed with sealing membrane to maintain the moisture. Each sample was performed in duplicate. The samples were incubated at room temperature 
for 30 days. Two untreated RMsf samples were prepared and incubated as the background RMsf.

Leachability test of arsenic in the RMsf by water elution

Considering the base conditions in the RM disposal area, the leachability test did not follow the standard TCLP test. A four-stage water elution test (Seidel et al. 2005) was carried out to determine the arsenic retention in the RMsf. Briefly, after aging, $1 \mathrm{~g}$ of the RMsf was suspended in $10 \mathrm{ml}$ of deionized water. The suspensions were shaken at $120 \mathrm{rpm}$ for $1 \mathrm{~h}$. After that, suspensions were centrifuged at $8,000 \mathrm{rpm}$ for $20 \mathrm{~min}$, and the supernatants were collected. The precipitates of the first elution were re-suspended in $10 \mathrm{ml}$ of deionized water and eluated again. Equal parts of all four supernatants were mixed and filtered by a Type HA filter $(0.45 \mu \mathrm{m}$, Millipore $)$, and the mixture was analyzed for water-soluble arsenic in the RMsf.

Arsenic fractionation using sequential extraction procedure

The sequential extraction procedure for arsenic fractionation used in this work was followed by Wenzel et al. (2001). The iron or acidifier treated RMsf sample (1 g) was placed in $50 \mathrm{ml}$ centrifugation tubes and $25 \mathrm{ml}$ of the extraction reagents (AR) were added sequentially. After each extraction step, the tubes containing the RMsf and the extractants were centrifuged for $15 \mathrm{~min}$ at 3,000 rpm. Solution entrapped in the remaining RMsf was collected in subsequent wash steps and combined with the corresponding extract (Table 1). The solution was filtered through $0.45 \mu \mathrm{m}$ cellulose acetate filter paper in PE-bottles and As concentrations were determined. The residual RMsf was used for the subsequent extraction steps. All extractions were performed in duplicate. Extracts were analyzed immediately after the extraction steps.
Analytical method

The method of RMsf pH measurement was as follows: an amount of $10 \mathrm{~g}$ RMsf was mixed with $100 \mathrm{ml}$ deionized water, the $\mathrm{pH}$ of supernatants was measured by a $\mathrm{pH}$ meter. The total arsenic was analyzed with an Atomic Fluorescence Spectrometer (AF-610A, Rayleigh Analytical Instrument Corp. China). The method of As(III) detection was using a method by Hug and Leupin (2003). Briefly, a pH 5 citrate buffer ( $0.5 \mathrm{M}$ disodium hydrogen citrate) was used instead of $\mathrm{HCl}$, and only $\mathrm{As}(\mathrm{III})$ (and no $\mathrm{As}(\mathrm{V})$ ) is converted to $\mathrm{AsH}_{3}$ under these conditions. Chlorine and sulfate radical anions were measured by ion chromatography (861, Metrohm). Alumina, iron, calcium, magnesium, sodium and silicon concentrations in leachability test were analyzed on Inductively Coupled Plasma Atomic Emission Spectroscopy (ICP-AES, Prodigy).

Most experiments were performed in triplicate; the mean values and standard deviation were considered. The control experiments showed no detectable arsenic, alumina, or iron adsorbed on the walls of the glass beaker or plastic centrifugal tube. To ascertain the reproducibility of results, a group of experiment was repeated twice, and the results were found to vary within $5 \%$.

\section{Results and discussions}

\section{Chemical compositions of RMsf}

The chemical compositions of the RMsf were shown in Table 2. Pentavalent arsenic was the main species, and the content of trivalent arsenic was less than $5 \%$ of the total amount of As. The arsenic concentration of the RMsf was about $1.1 \times 10^{-2} \pm 2.0 \times 10^{-3} \mathrm{mg} / \mathrm{g}$. The arsenic concentration of the RMsf in this work was lower than $1.1 \times 10^{-1} \mathrm{mg} / \mathrm{g}$ which was reported during Hungarian reservoir wall cracks in Doyle (2010). The arsenic in the RMsf may come from the iron-rich bauxite, which was

Table 1 Sequential extraction procedure for arsenic

\begin{tabular}{|c|c|c|c|c|}
\hline Fraction & Extractant & Extraction conditions & SSR & Wash step \\
\hline 1 & $\left(\mathrm{NH}_{4}\right)_{2} \mathrm{SO}_{4}(0.05 \mathrm{M})$ & $4 \mathrm{~h}$ Shaking, $20^{\circ} \mathrm{C}$ & $1: 25$ & \\
\hline 2 & $\left(\mathrm{NH}_{4}\right) \mathrm{H}_{2} \mathrm{PO}_{4}(0.05 \mathrm{M})$ & $16 \mathrm{~h}$ Shaking, $20^{\circ} \mathrm{C}$ & $1: 25$ & \\
\hline 3 & $\mathrm{NH}_{4}$-oxalate buffer(0.2 M);pH 3.25 & $4 \mathrm{~h}$ Shaking in the dark, $20^{\circ} \mathrm{C}$ & $1: 25$ & $\begin{array}{r}\text { NH4-oxalate }(0.2 \mathrm{M}) ; \mathrm{pH} \text { 3.25 SSR } \\
1: 12.5 ; 10 \text { min shaking in the dark }\end{array}$ \\
\hline 4 & $\begin{array}{l}\text { NH4-oxalate buffer( }(0.2 \mathrm{M}) ;+ \text { axcorbic } \\
\text { acid }(0.1 \mathrm{M}) \mathrm{pH} 3.25\end{array}$ & $\begin{array}{l}30 \mathrm{~min} \text { in a water basin at } \\
96 \pm 3{ }^{\circ} \mathrm{C} \text { in the light }\end{array}$ & $1: 25$ & $\begin{array}{l}\text { NH4-oxalate }(0.2 \mathrm{M}) ; \mathrm{pH} 3.25 \text { SSR } \\
1: 12.5 ; 10 \text { min shaking in the dark }\end{array}$ \\
\hline 5 & $\mathrm{HNO}_{3} / \mathrm{H}_{2} \mathrm{O}_{2}$ & Microwave digestion & $1: 50^{\mathrm{a}}$ & \\
\hline
\end{tabular}

SSR soil solution ratio

a After the digestion 
Table 2 Chemical compositions of RMsf (mg/g)

\begin{tabular}{lllllllll}
\hline$\%$ & As & $\mathrm{Si}$ & $\mathrm{Fe}$ & $\mathrm{Al}$ & $\mathrm{Ca}$ & $\mathrm{Ti}$ & $\mathrm{Na}$ & $\begin{array}{l}\text { Moisture } \\
\text { content }\end{array}$ \\
\hline RMsf & $1.1 \times 10^{-2}$ & 14.2 & 20.9 & 12.2 & 1.5 & 1.1 & 6.6 & $15-20$ \\
\hline
\end{tabular}

widely used in bayer alumina production process. The environmental risk of arsenic in RM should be focused on during alumina product.

The RMsf $\mathrm{pH}$ was measured as $10.8 \pm 0.2$, and the amount of alkalinities in the RMsf was about $13.5 \pm 2.0 \mathrm{mg} / \mathrm{g}$. The main mineral phases of the RMsf were hematite, anatase, quartz, $\mathrm{CaCO}_{3}$ and $\alpha-\mathrm{Al}(\mathrm{OH})_{3}$. There was little clear evidence for arsenic contained mineral phase consisted in the RMsf.

Mobility of arsenic in the RMsf washed by water

After 30-day aging, the $\mathrm{pH}$ of the RMsf was shown in Fig. 2. The untreated $\mathrm{RMsf} \mathrm{pH}$ was $10.9 \pm 0.1 . \mathrm{FeSO}_{4}$ or WA significantly decreased the RMsf $\mathrm{pH}$ after aging. The $\mathrm{pH}$ of RMsf with $6 \% \mathrm{FeSO}_{4}$ treated decreased to lower than 6.0. Oxidation of $\mathrm{Fe}$ (II) to $\mathrm{Fe}(\mathrm{III})$ by dissolved oxygen occurred, and the reaction could be described as Eq. (1). Hydrolysis and precipitation of $1 \mathrm{~mol} \mathrm{Fe}(\mathrm{III})$-hydroxides resulted in the release of $3 \mathrm{~mol} \mathrm{H}^{+}$as described in Eq. (2). It was shown in Fig. 2 that $60 \mathrm{mg} / \mathrm{g} \mathrm{FeSO}_{4} \cdot 7 \mathrm{H}_{2} \mathrm{O}$ was adequate for the alkalinities neutralization in RMsf.

$\mathrm{Fe}^{2+}+(1 / 4) \mathrm{O}_{2}+\mathrm{H}^{+} \rightarrow \mathrm{Fe}^{3+}+(1 / 2) \mathrm{H}_{2} \mathrm{O}$

$\mathrm{Fe}^{3+}+3 \mathrm{H}_{2} \mathrm{O} \rightarrow \mathrm{Fe}(\mathrm{OH})_{3}+3 \mathrm{H}^{+}$.

$\mathrm{CO}_{2}$ was widely reported for neutralizing RM (Sahu et al. 2010). However, the $\mathrm{pH}$ of the $\mathrm{CO}_{2}$ treated RMsf showed little changes after 30-day aging in this work. There may be several reasons for the poor acidification

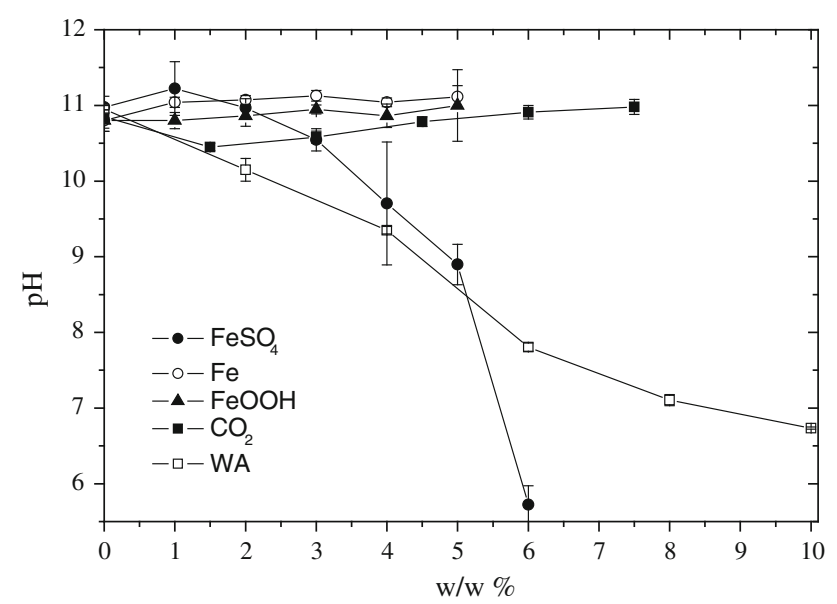

Fig. 2 Variations of $\mathrm{pH}$ in treated RMsf with different amendments. The treated RMsf samples were aged for 30 days efficiency. Firstly, the acidification efficiency of $\mathrm{CO}_{2}$ was weakened by the aerator, part of $\mathrm{CO}_{2}$ escaped from the unsealed cover. Secondly, the hydrolysis process of $\mathrm{CO}_{2}$ could be described in Eq. (3)

$\mathrm{CO}_{2}+\mathrm{H}_{2} \mathrm{O} \rightleftarrows \mathrm{H}_{2} \mathrm{CO}_{3}^{*} \rightleftarrows \mathrm{HCO}_{3}^{-}+\mathrm{H}^{+} \rightleftarrows \mathrm{CO}_{3}^{2-}+2 \mathrm{H}^{+}$.

It was reported that $\mathrm{CO}_{3}{ }^{2-}$ and $\mathrm{HCO}_{3}{ }^{-}$were the main alkalinities in the RM ( $\mathrm{Li}$ et al. 2012). These components inhibited the hydrolysis of $\mathrm{CO}_{2}$ therefore decrease the acidification efficiency. Thirdly, a part of alkalinities in the RMsf may not be sufficiently contacted with $\mathrm{CO}_{2}$ during the aeration.

ZVI showed little effects on the RMsf pH. Reactions (4)-(6) roughly represent the relevant processes that may be involved in the formation of iron species from ZVI. The chemical reactions of ZVI in RMsf were inhibited because of the alkaline conditions.

$\mathrm{Fe}^{0}+2 \mathrm{H}_{2} \mathrm{O} \rightarrow \mathrm{Fe}(\mathrm{II})+\mathrm{H}_{2}+2 \mathrm{OH}^{-}$

$\mathrm{Fe}^{0}+\mathrm{H}_{2} \mathrm{O}+1 / 2 \mathrm{O}_{2} \rightarrow \mathrm{Fe}(\mathrm{II})+2 \mathrm{OH}^{-}$

$\mathrm{Fe}^{0}+2 \mathrm{Fe}(\mathrm{III}) \rightarrow 3 \mathrm{Fe}(\mathrm{II})$.

The arsenic concentrations in the water eluates after fourfold water elusion were shown in Fig. 3. The water extracts collected after fourfold elution of the untreated RMsf contained $3.5 \times 10^{-2} \pm 9 \times 10^{-4} \mathrm{mg} / \mathrm{l}$ As, which corresponds to an As solubility of $1.4 \times 10^{-3} \pm 3.6 \times$ $10^{-5} \mathrm{mg} / \mathrm{g}$. About $12.7 \%$ of the total arsenic in the RMsf was extractable after fourfold water elusion.

As shown in Fig. 3, $\mathrm{FeSO}_{4}$ was the most effective As amendments. When the RMsf was treated with $30 \mathrm{mg} / \mathrm{g}$ $\mathrm{FeSO}_{4} \cdot 7 \mathrm{H}_{2} \mathrm{O}$, the concentration of As species in the water eluates decreased below the analytical detection limit of $2 \mu \mathrm{g} / \mathrm{l}$. Compared to the untreated RMsf, about $99 \%$ of As

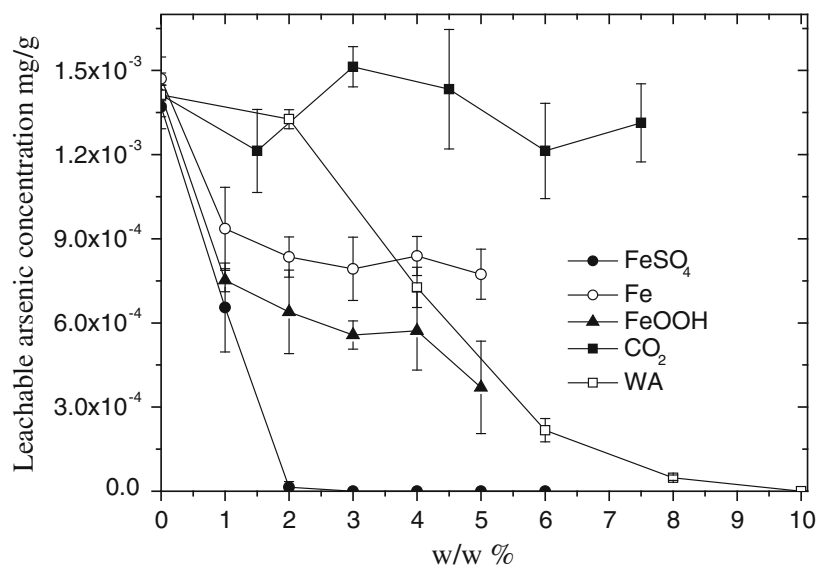

Fig. 3 Arsenic concentrations in the water eluates after fourfold water elusion of treated RMsf. The treated RMsf samples were aged for 30 days 
was removed from the solution with $2 \% \mathrm{FeSO}_{4} \cdot 7 \mathrm{H}_{2} \mathrm{O}$ added. The RMsf $\mathrm{pH}$ remained higher than 10.0 with $20 \mathrm{mg} / \mathrm{g} \mathrm{FeSO} \mathrm{F}_{4} \cdot 7 \mathrm{H}_{2} \mathrm{O}$ added. In the base circumstance, adsorption of arsenic on the surface of iron oxide was inhibited. The co-precipitation of iron and arsenic should contribute to the decreased portion of mobile arsenic in RMsf.

Compared to the untreated RMsf, about $97 \%$ of As was removed from the leachates with $8 \%$ WA added. Less than $80 \mathrm{mg} / \mathrm{g}$ WA addition rate was not sufficient to stabilize As effectively. The RMsf $\mathrm{pH}$ was 7.1 with $80 \mathrm{mg} / \mathrm{g}$ WA treated. The total alkalinities in the RMsf decreased with WA added. Neutral condition of the RMsf was advantaged for arsenic adsorption on the hematite.

An amount of $50 \mathrm{mg} / \mathrm{g}$ ZVI and ferrihydrite was effective to immobilize 45 and $74 \%$ mobile arsenic in RMsf, respectively. The RMsf $\mathrm{pH}$ with ZVI or ferrihydrite added was not significantly changed. It was well known that hydroxyl was replaced by arsenic on the surface of iron oxide. Therefore, arsenic immobilization by iron salts was inhibited by the high alkalinities in the RMsf. Meanwhile, the mobile arsenic in the RMsf showed no significantly decreased with $\mathrm{CO}_{2}$ added. The results were accordance with Fig. 2 that $\mathrm{CO}_{2}$ was not effective in RMsf acidification in this work.

Chemical fractionation of arsenic using sequential extractions

The arsenic 5-step sequential extraction procedure was applied in the RMsf. Five fractions of As in RMsf were shown in Fig. 4. The non-specifically bound fraction was targeting the easily exchangeable, outer-sphere complexes of As. The non-specifically bound As in original RMsf was $3.0 \times 10^{-4} \mathrm{mg} / \mathrm{g}$, which was much less compared to the leachable As after 4-step water elusion. The 4-step water elusion or the 5-step sequential extraction procedures were both indirect methods for evaluating the potential migration of As in RMsf. The non-specifically bound fraction in sequential extraction procedure was only one part of the potential migration As in the RMsf. The content of the nonspecifically bound As in RMsf decreased to $6.3 \times 10^{-5}$ and $1.3 \times 10^{-4} \mathrm{mg} / \mathrm{g}$ with $5 \%$ ferrihydrite and ZVI added, respectively. The non-specifically bound As in the RMsf was below the detection limit with $2 \% \mathrm{FeSO}_{4} \cdot 7 \mathrm{H}_{2} \mathrm{O}$ or $8 \% \mathrm{WA}$ added. The non-specifically bound As in the RMsf showed little changes with $\mathrm{CO}_{2}$ added. The efficiencies of reducing the non-specifically bound As in RMsf by $\mathrm{FeSO}_{4}$ or WA treated were higher than ferrihydrite or ZVI. The effects of amendments on arsenic immobilization in RMsf were similar compared to 4-step water elusion and non-specifically bound As evaluation.

EXAFS studies of As adsorption on ferrihydrite and goethite have shown the existence of three distinct innersphere surface species of As, including monodentate, bidentate-binuclear and bidentate-mononuclear complexes of different stability and formation kinetics (Manning et al. 1998; Sherman and Randall 2003; Waychunas et al. 1993). Wenzel et al. (2001) suggested that $\mathrm{NH}_{4} \mathrm{H}_{2} \mathrm{PO}_{4}$ was extracting varied proportions of these inner-sphere surface complexes of As, targeting the specifically bound As in the solid phase. $\left(\mathrm{NH}_{4}\right)_{2} \mathrm{SO}_{4}$ and $\mathrm{NH}_{4} \mathrm{H}_{2} \mathrm{PO}_{4}$ extractable As are associated with surfaces of solid phases. The contents of As on the surface of RMsf decreased from $5.3 \times 10^{-3}$ to $3.3 \times 10^{-3}$ and $3.5 \times 10^{-3} \mathrm{mg} / \mathrm{g}$ with $5 \% \mathrm{FeSO}_{4} \cdot 7 \mathrm{H}_{2} \mathrm{O}$ and $8 \%$ WA added, respectively. The surface-associated arsenic of the RMsf was $5.0 \times 10^{-3}$ and $4.8 \times 10^{-3} \mathrm{mg} / \mathrm{g}$ with ferrihydrite and ZVI added, respectively. $\mathrm{CO}_{2}$ showed little effects on the surface-associated As in the RMsf. The proportions of the specifically bound As on the surface of RMsf increased with the iron oxide added. It was well known that neutral or acid condition was advantaged for
Fig. 4 Chemical fractionation of As by 5 -step sequential extraction procedure in treated $\mathrm{RMsf}$

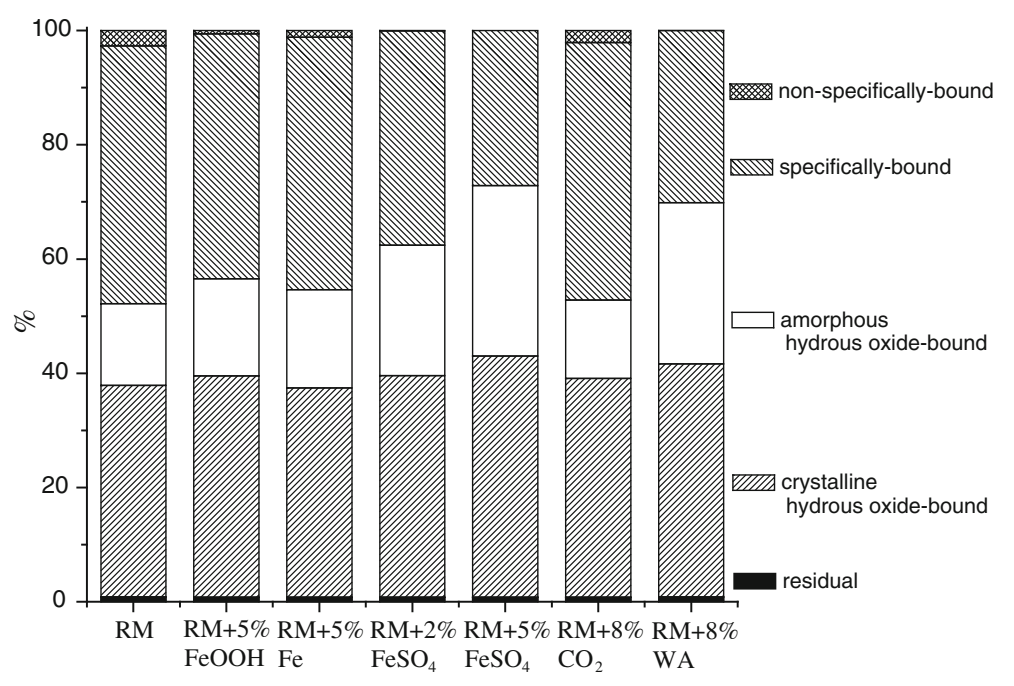


arsenic adsorption on iron oxide. More amounts of arsenic could be adsorbed on the surface of hematite when $\mathrm{pH}$ decreased with WA or $\mathrm{FeSO}_{4}$ added. It was reported that $\mathrm{Fe} / \mathrm{Al}$ oxides adsorbed As was not stable in alkaline soils (Datta et al. 2007). Part of specifically bound As could migrate with water in the RMsf.

Wenzel et al. (2001) suggested that $\mathrm{NH}_{4}$-oxalate was effective for targeting amorphous oxyhydroxides of both $\mathrm{Fe}$ and Al. Amorphous hydrous oxide-bound As in the untreated RMsf was $1.5 \times 10^{-3} \mathrm{mg} / \mathrm{g}$. This part of arsenic in the RMsf may be combined with $\mathrm{Fe}$ or $\mathrm{Al}$ during the hydroxide formation process, which was covered by $\mathrm{Fe}$ or $\mathrm{Al}$ hydroxide. The $\mathrm{Fe}$ or $\mathrm{Al}$ hydrous oxide bound arsenic in RMsf increased to $3.6 \times 10^{-3}$ and $3.3 \times 10^{-3}$ with $5 \%$ $\mathrm{FeSO}_{4}$ and $8 \% \mathrm{WA}$ added, respectively. More amount of $\mathrm{FeSO}_{4}$ increased the proportion of amorphous hydrous oxide-bound As in the RMsf. This part of arsenic was slightly increased to $2.0 \times 10^{-3}$ and $1.9 \times 10^{-3} \mathrm{mg} / \mathrm{g}$ with ferrihydrite and ZVI added, respectively. High alkalinities inhibited the hydroxylation process of ferrihydrite or ZVI. Amorphous hydrous oxide-bound As was more stable than surface-associated arsenic. The result of arsenic chemical fractionation was assistant to the 4-step water elusion test. $\mathrm{FeSO}_{4}$ or WA was more effective in increasing the stable As species than ferrihydrite or ZVI.

XRD showed little evidence for the new generated arsenic contained crystals in RMsf after amendments. The results of arsenic fractionation showed that the crystalline hydrous oxide-bound As in the RMsf slightly increased with $\mathrm{FeSO}_{4}$ or WA added. The following reactions could be expected in the RMsf. Green rust was formed under anaerobic conditions with ferrous added. Some part of green rust could transform to goethite after oxidation (Amstaetter et al. 2010). Part of hematite could dissolve in WA at first, then the $\mathrm{Fe}^{3+}$ may precipitate in the alkaline conditions. It was widely reported that ferrihydrite was transformed to goethite after a period of time (Liu et al. 2010). The crystalline hydrous oxide-bound As or residue As in the RMsf may consist in mineral phase. These parts of arsenic were most stable species in the RMsf. Amendments showed slightly effects on the crystalline hydrous oxide-bound or residue As in the RMsf. It was possible that arsenic contained mineral phase was formed after amendments were added. However, XRD and chemical fractionation tests cannot provide sufficient evidence for the novel arsenic contained mineral phase.

Mobility of anionic and cationic in the RMsf

The main anionic and cationic in the leachates of fourfold water elusion were tested. These results were used to evaluate the mobility of the main anionic and cationic. The following elements were evaluated in the leachates, the concentrations of Sodium(Na), Calcium(Ca), Aluminum(Al), etc. in the leachates were evaluated. The concentration of $\mathrm{Pb}, \mathrm{Zn}, \mathrm{Mn}, \mathrm{Ni}$ orCr in the leachates was below the detection limit. The concentrations of $\mathrm{Si}, \mathrm{P}, \mathrm{K}$ in the RMsf were lower than $1 \times 10^{-3} \mathrm{mg} / \mathrm{g}$. The concentrations of leachable $\mathrm{Na}$ in the RMsf was about $15.6 \pm 2.8 \mathrm{mg} / \mathrm{g}$, and $\mathrm{Na}$ mobility was not significantly changed during the RMsf treatment. The concentration of $\mathrm{Al}, \mathrm{Ca}, \mathrm{Fe}, \mathrm{Cl}^{-}, \mathrm{NO}_{3}{ }^{-}$or $\mathrm{SO}_{4}{ }^{2-}$ in the leachates was shown in Tables 3 and 4.

Leachable $\mathrm{Si}$ in the RMsf was between $4.2 \times 10^{-2}$ and $5.4 \times 10^{-2} \mathrm{mg} / \mathrm{g}$ with ZVI and ferrihydrite added, respectively. The concentration of mobile $\mathrm{Si}$ in the RMsf decreased sharply with $\mathrm{FeSO}_{4}$ or WA added. It was reported that silicate was adsorbed by iron hydroxide (Davis et al. 2001). Active iron hydroxide in suitable $\mathrm{pH}$ conditions could decrease the mobile silicate in the RMsf. The leachable $\mathrm{Al}$ in the RMsf decreased sharply with $\mathrm{FeSO}_{4}$ or WA added. Alumina precipitated in neutral conditions after $\mathrm{FeSO}_{4}$ or WA was added in the RMsf. The concentration of mobile $\mathrm{Ca}$ in the RMsf slightly increased after $\mathrm{FeSO}_{4}$ or WA treatment. It was well known that calcium was advantaged for reducing arsenic mobility in the solid phase. Arsenic-calcium co-precipitation could also be an important process for arsenic immobilization in the RMsf. The environmental risk of mobile cations in the RMsf before or after the arsenic treatment was not significant.

The $\mathrm{Cl}^{-}$concentration in the leachates after fourfold elusions was significantly increased with WA added. The mobile sulfate concentration in the RMsf was increased from 19.9 to $44.4 \mathrm{mg} / \mathrm{g}$ with $5 \% \mathrm{FeSO}_{4}$ added. The mobile nitrate concentration showed little difference during the RMsf treatment. The environmental risk of anions in the RMsf should be evaluated when WA or ferrous was used in the arsenic chemical immobilization.

\section{Cost evaluation of arsenic chemical immobilization} in RMsf

The prices of WA and $\mathrm{FeSO}_{4} \cdot 7 \mathrm{H}_{2} \mathrm{O}$ were about 6.15 and 23.3 USD per ton. Figure 3 showed that $2 \% \mathrm{FeSO}_{4} \cdot 7 \mathrm{H}_{2} \mathrm{O}$ or $8 \%$ WA was effective in arsenic immobilization in the RMsf. The cost of arsenic immobilization with $\mathrm{FeSO}_{4}$ and WA added was 0.47 and 0.49 USD per ton, respectively. The cost of industrial ZVI was more than 150 USD per ton. Ferrihydrite was synthesized by adding $\mathrm{FeCl}_{3}$ in $\mathrm{Na}_{2} \mathrm{CO}_{3}$ solutions. The RMlf could be used instead of $\mathrm{Na}_{2} \mathrm{CO}_{3}$ solutions in practical conditions. The cost of $\mathrm{FeCl}_{3}$ was more than 400 USD per ton. The cost of ZVI or ferrihydrite was significantly higher than WA or $\mathrm{FeSO}_{4} \cdot 7 \mathrm{H}_{2} \mathrm{O}$. WA or $\mathrm{FeSO}_{4} \cdot 7 \mathrm{H}_{2} \mathrm{O}$ should be capable for the RMsf treatment when $\mathrm{Cl}^{-}$or $\mathrm{SO}_{4}$ did not exceed the environment capacity. 


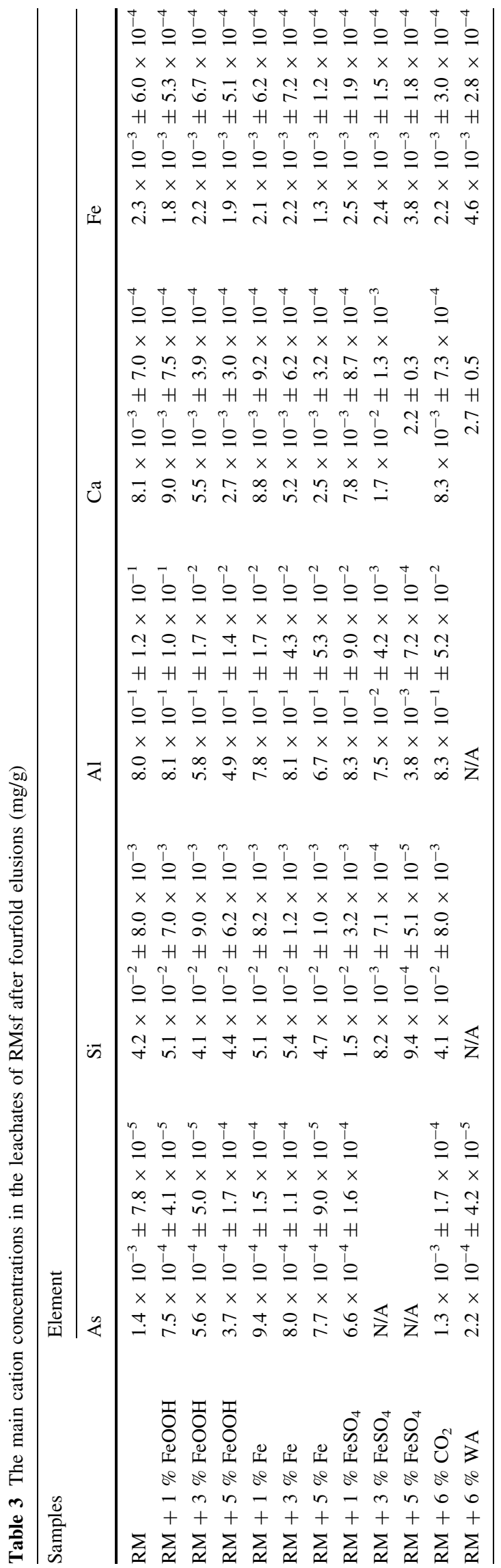

Table 4 The main anion concentrations in the leachates of RMsf after fourfold elusions $(\mathrm{mg} / \mathrm{g})$

\begin{tabular}{llll}
\hline Samples & \multicolumn{2}{l}{ Element } \\
\cline { 2 - 4 } & \multicolumn{1}{l}{$\mathrm{Cl}^{-}$} & $\mathrm{NO}_{3}{ }^{-}$ & \multicolumn{1}{l}{$\mathrm{SO}_{4}{ }^{-}$} \\
\hline $\mathrm{RM}$ & $2.9 \pm 0.3$ & $1.8 \pm 0.2$ & $19.9 \pm 1.2$ \\
$\mathrm{RM}+5 \% \mathrm{FeOOH}$ & $2.5 \pm 0.2$ & $1.4 \pm 0.3$ & $15.9 \pm 0.3$ \\
$\mathrm{RM}+5 \% \mathrm{Fe}$ & $2.1 \pm 0.1$ & $1.8 \pm 0.3$ & $20.9 \pm 0.9$ \\
$\mathrm{RM}+5 \% \mathrm{FeSO}_{4}$ & $2.2 \pm 0.3$ & $1.9 \pm 0.2$ & $44.4 \pm 3.6$ \\
$\mathrm{RM}+6 \% \mathrm{CO}_{2}$ & $2.8 \pm 0.3$ & $1.7 \pm 0.2$ & $20.2 \pm 1.2$ \\
$\mathrm{RM}+6 \% \mathrm{WA}$ & $14.1 \pm 1.2$ & $1.8 \pm 0.2$ & $19.1 \pm 1.2$ \\
\hline
\end{tabular}

It was reported that $0.07-0.45$ USD was cost for arsenic immobilization in one ton of RM ( $\mathrm{Li}$ et al. 2012). 30-40\% (w/w) RMsf consisted in the RM. Therefore, 0.18-1.50 USD was estimated for arsenic immobilization in one ton of RMsf. Taking into account the loss of alumina in the RMlf, arsenic treatment in the RMsf should be more costeffective.

\section{Conclusion}

The efficiencies of arsenic chemical immobilization in the RMsf by ZVI, ferrous, ferrihydrite, WA or $\mathrm{CO}_{2}$ were evaluated. Alkalinities and the iron oxide were the main chemicals in the RMsf. Compared with alkalinities used in soils and tailing materials, acidic materials should be effective in the RMsf treatment. Ferrous and WA were cost-effective in reducing arsenic mobility in the RMsf. The mobile $\mathrm{Cl}^{-}$and $\mathrm{SO}_{4}{ }^{2-}$ concentration sharply increased in the RMsf during WA and $\mathrm{FeSO}_{4} \cdot 7 \mathrm{H}_{2} \mathrm{O}$ treatment, respectively. ZVI or ferrihydrite was less effective and more expensive than WA or $\mathrm{FeSO}_{4} \cdot 7 \mathrm{H}_{2} \mathrm{O}$ for As chemical immobilization in the RMsf. However, the anions' concentrations showed little changed during ZVI or ferrihydrite treatment. $\mathrm{CO}_{2}$ was not effective in arsenic immobilization in the RMsf because of the insufficient hydrolysis and inadequate contact with alkalinities.

Acknowledgments Financial support provided by the National High Technology R\&D Program (863) from Ministry of Science \& Technology of China (under Grant No. 2008AA06A409-3, 2011AA060701), and Shanghai Tongji Gao TingYao Environmental Science \& Technology Development Foundation.

\section{References}

Amstaetter K, Borch T, Larese-Casanova P, Kappler A (2010) Redox transformation of arsenic by $\mathrm{Fe}(\mathrm{II})$-activated goethite (alphaFeOOH). Environ Sci Technol 44:102-108

Bang S, Korfiatis GP, Meng X (2005) Removal of arsenic from water by zero-valent iron. J Hazard Mater 121:61-67 
Datta R, Makris KC, Sarkar D (2007) Arsenic fractionation and bioaccessibility in two alkaline Texas soils incubated with sodium arsenate. Arch Environ Contam Toxicol 52:475-482

Davis CC, Chen HW, Edwards M (2001) Modeling silica sorption to iron hydroxide. Environ Sci Technol 36:582-587

Doyle P (2010) Hungary toxic disaster-entire villages to be abandoned. http://www.rense.com/general92/d32s.htm

Hug S, Leupin O (2003) Iron-catalyzed oxidation of arsenic (III) by oxygen and by hydrogen peroxide: $\mathrm{pH}$-dependent formation of oxidants in the Fenton reaction. Environ Sci Technol 37:2734-2742

Klauber C, Gräfe M, Power G (2009) Review of bauxite residue "reuse" options

Li Y, Wang J, Luan Z, Liang Z (2010) Arsenic removal from aqueous solution using ferrous based red mud sludge. J Hazard Mater 177:131-137

Li Y, Wang J, Peng X, Ni F, Luan Z (2012) Evaluation of arsenic immobilization in red mud by $\mathrm{CO} 2$ or waste acid acidification combined ferrous (Fe 2+) treatment. J Hazard Mater 199-200: $43-50$

Liu H, Ma M, Qin M, Yang L, Wei Y (2010) Studies on the controllable transformation of ferrihydrite. J Solid State Chem 183:2045-2050

Manning BA, Fendorf SE, Goldberg S (1998) Surface structures and stability of arsenic(III) on goethite: spectroscopic evidence for inner-sphere complexes. Environ Sci Technol 32:2383-2388

Miretzky P, Cirelli AF (2010) Remediation of arsenic-contaminated soils by iron amendments: a review. Crit Rev Environ Sci Technol 40:93-115

Sahu RC, Patel RK, Ray BC (2010) Neutralization of red mud using CO2 sequestration cycle. J Hazard Mater 179:28-34
Seidel H, Görsch K, Amstätter K, Mattusch J (2005) Immobilization of arsenic in a tailings material by ferrous iron treatment. Water Res 39:4073-4082

Sherman DM, Randall SR (2003) Surface complexation of arsenic(V) to iron(III) (hydr)oxides: structural mechanism from ab initio molecular geometries and EXAFS spectroscopy. Geochim Cosmochim Acta 67:4223-4230

Soner Altundogan H, Altundogan S, Tümen F, Bildik M (2000) Arsenic removal from aqueous solutions by adsorption on red mud. Waste Manage 20:761-767

Sushil S, Batra V (2008) Catalytic applications of red mud, an aluminium industry waste: a review. Appl Catal B Environ 81:64-77

Tokoro C, Yatsugi Y, Koga H, Owada S (2009) Sorption mechanisms of arsenate during coprecipitation with ferrihydrite in aqueous solution. Environ Sci Technol 44:638-643

Waychunas G, Rea B, Fuller C, Davis J (1993) Surface chemistry of ferrihydrite: part 1. EXAFS studies of the geometry of coprecipitated and adsorbed arsenate. Geochim Cosmochim Acta 57:2251-2269

Wenzel WW, Kirchbaumer N, Prohaska T, Stingeder G, Lombi E, Adriano DC (2001) Arsenic fractionation in soils using an improved sequential extraction procedure. Anal Chim Acta 436:309-323

Xenidis A, Stouraiti C, Papassiopi N (2010) Stabilization of Pb and As in soils by applying combined treatment with phosphates and ferrous iron. J Hazard Mater 177:929-937

Zhang M, Pu J (2011) Mineral materials as feasible amendments to stabilize heavy metals in polluted urban soils. J. Environ Sci China 23:607-615 